\title{
Pattern of Alcohol Consumption in Registered Users of a Family Health Unit
}

\author{
Jerssika Karla Sobreira da Silva1, Fernanda Jorge Guimarães1, \\ Jaqueline Galdino Albuquerque Perrelli1, Zailde Carvalho dos Santos ${ }^{1}$, \\ Lorita Marlena Freitag Pagliuca ${ }^{2 *}$ \\ ${ }^{1}$ Department of Nursing, Universidade Federal de Pernambuco, Vitória de Santo Antão, Brazil \\ ${ }^{2}$ Department of Nursing, Universidade Federal do Ceará, Fortaleza, Brazil \\ Email: ${ }^{*}$ pagliuca@ufc.br
}

Received 2 April 2014; revised 3 May 2014; accepted 11 May 2014

Copyright (C) 2014 by authors and Scientific Research Publishing Inc.

This work is licensed under the Creative Commons Attribution International License (CC BY). http://creativecommons.org/licenses/by/4.0/

(c) (i) Open Access

\section{Abstract}

The alcohol abuse is associated with a wide range of social, health and legal problems to analyze the pattern of alcohol consumption of users of a Family Health Unit. A descriptive, cross-sectional study with a quantitative approach, conducted with 207 users of a Family Health Unit who responded the Alcohol Use Disorders Identification Test. Data were analyzed with the aid of the STATA/SE 12.0 software. To analyze the association of the variables, the chi-square and Fisher's exact test were used. Of the participants, $40.6 \%$ presented abusive consumption of alcohol, which is strongly associated to the male sex, single, between 18 and 30 years of age, who have no religion and some sort of occupation. There was no relation with monthly income and education. Screening and prevention programs to alcohol abuse are important for the most vulnerable group in the primary health care.

\section{Keywords}

Nursing, Alcoholism, Primary Health Care

\section{Introduction}

Throughout the world, the abusive consumption of alcohol has been highlighted among the ten main causes which lead to premature death among the adult population. The abuse of alcohol is related to problems in several social scopes, among them regarding work, the family, the physical damage as well as the legal risk [1] [2].

In Brazil, the data showed that $23 \%$ have already drunk alcoholic beverages, and they also presented prob-

\footnotetext{
${ }^{*}$ Corresponding author.
} 
lems due to this consumption; $28 \%$ have abusively drunk alcoholic beverages, at least once in the period of one year; $20 \%$ of those users presented higher frequency than weekly and $20 \%$ used alcohol at home. Other additional information revealed that $3 \%$ of the Brazilian population took too much alcohol and $9 \%$ of them presented alcoholic dependence [3] [4].

One of the ten main causes of morbidity and mortality in Brazil is the use of alcohol, but the prevalence on this type of disease has little research in the area of primary attention to health, although a study made shows that a considerable frequency of this type of disease has little research in the area of primary attention to health, however a study made shows considerable frequency of this type of disease in the areas covered by this type of service [5].

In this case, due to exaggerated and indiscriminate consumption of alcohol, to the problems caused by its use and to the importance of the actions in the scenario of primary attention to health, the evaluation of the pattern of the alcohol consumption by users of the primary attention is relevant, keeping in mind the identification of the risk factors concomitant with such disorder, and so, the establishment of strategies of promotion and prevention of health, and the widening of the knowledge regarding this theme in order to have possible comparisons with studies are already made [5].

Facing the range of information referring to this problem, it is extremely relevant to study and recognize the subject susceptible to the factors which can influence the abusive consumption of alcoholic beverages even before the occurrence of clinical affections resulting from this consumption. Such actions are found in the scope of early acting of primary health.

As described above, the study has the objective to analyze the standard of alcohol consumption by registered users at a Family Health Unit (FHU), analyzing the category variables and identifying the different patterns of alcohol consumption of these users.

\section{Method}

It is a descriptive cross-sectional study with quantitative approach. The option for the cross-sectional study was made, once it allows the mapping of the distribution of a phenomenon in the population under study, with the interference of the researcher, which limits a sample of the population and evaluates the variables within this sample [6].

The study was approved by the Committee of Ethics in Research of the Universidade Federal de Pernambuco/ Pernambuco/Brazil. The population of the study was formed by registered users at a Family Health Unit. To form the sample, the following subjects were selected according to the following criteria of eligibility: subjects being older than 18 years and from the male and female sex. The subjects who had some kind of cognitive deficit were excluded from the study, which could make them unable to respond to the instrument of data collection.

As to the sample calculation, a formula for cross-sectional studies with finite population was used, which considered the following parameters: number of subjects older than 18 years registered at the FHU, locus of the study, level of confidence of 95\%, prevalence of abusive use of alcohol of 18.3\% [7] and sample error margin of $5 \%$. The estimated size of the sample was 207 users. The process of sampling was simple random probabilistic.

The data were collected through a social-demographic questionnaire and the Alcohol Use Disorder Identification Test (AUDIT), which is made up by ten questions in which the score can vary from zero to forty points. Four standards can be identified regarding the use of alcohol or risk zones, that are: use of low risk or risk zone I (0 to 7 points), hazardous drinking or risk zone II (8 to 15 points), harmful drinking or risk zone III (16 to 19 points) and alcohol dependence or risk zone IV (20 to 40 points). The first three questions of the AUDIT evaluate the quantity, frequency and drunkenness; the following three questions, the symptoms of dependence; and the last four questions, evaluate the risk of harmful consequences to the user. The necessary time to fill in the questionnaire was approximately five minutes [3] [8].

The procedure for the data collection was made through a draw of participants who were invited to participate in the study. In this study, the following variables were investigated: sex, age, marital status, schooling, income, occupation and religion.

In order to analyze the data the STATA/SE 12.0 software was used. For this study the cut-off with the final score of 8.0 of AUDIT was used. All the tests were applied of $95 \%$ of confidence. To verify the existence of association between the punctuation of the AUDIT and the variables of the study the chi-square test and the Fisher's Exact Test were used. 


\section{Results}

Table 1 presents the main socio-demographic data, in which most of the subjects are female (51.7\%), with age average between 30 to 59 years (47.8\%), incomplete or complete high school (38.2\%), married (54.6\%), catholic (46.4\%), employed (45.9\%) and with monthly income until one minimum wage (49.8\%).

Through the final score of the AUDIT questionnaire, it was identified that $40.6 \%$ of the interviewed users presented risk consumption for alcoholic beverages.

Data of Table 2 show the significant statistically association between the risk consumption of alcohol and the variables gender, age, religion, marital status and occupation. There was no significant relation between the variables monthly income and schooling.

Table 1. Socio-demographic characteristics of the users of the FHU under study, Vitória de Santo Antão, Pernambuco, Brazil (n = 207).

\begin{tabular}{|c|c|c|}
\hline Variables & No. & $\%$ \\
\hline \multicolumn{3}{|l|}{ Gender } \\
\hline Female & 107 & 51.7 \\
\hline Male & 100 & 48.3 \\
\hline \multicolumn{3}{|l|}{ Age (years) } \\
\hline Under 30 & 70 & 33.8 \\
\hline 30 to 59 & 99 & 47.8 \\
\hline 60 or more & 38 & 18.4 \\
\hline \multicolumn{3}{|l|}{ Religion } \\
\hline Catholic & 96 & 46.4 \\
\hline Evangelic & 35 & 16.9 \\
\hline Without religion & 76 & 36.7 \\
\hline \multicolumn{3}{|l|}{ Marital status } \\
\hline Single & 72 & 34.8 \\
\hline Married & 113 & 54.6 \\
\hline Widow & 16 & 7.7 \\
\hline Divorced & 6 & 2.9 \\
\hline \multicolumn{3}{|l|}{ Monthly income $^{a}$} \\
\hline Without income & 76 & 36.7 \\
\hline Until 1 minimum wage & 103 & 49.8 \\
\hline Between 1 and 2 minimum wages & 28 & 13.5 \\
\hline \multicolumn{3}{|l|}{ Schooling } \\
\hline Illiterate & 59 & 28.5 \\
\hline 1 to 9 years of study & 66 & 31.9 \\
\hline 10 to 12 years of study & 79 & 38.2 \\
\hline Above 12 years of study & 3 & 1.4 \\
\hline \multicolumn{3}{|l|}{ Occupation } \\
\hline Employed & 95 & 45.9 \\
\hline Unemployed & 77 & 37.2 \\
\hline Retired/Pensioner & 35 & 16.9 \\
\hline
\end{tabular}

${ }^{\mathrm{a}}$ Mininum wage $=\mathrm{R} \$ 724.00$ corresponding approximately to US\$306.00. 
Table 2. Association between the risk consumption of alcohol and socio-demographic characteristics of the users of the FHU under study, Vitória de Santo de Antão, Pernambuco, Brazil (no. = 207).

\begin{tabular}{|c|c|c|c|}
\hline \multirow{3}{*}{ Variables } & \multicolumn{2}{|c|}{ Risk consumption } & \multirow{3}{*}{ p-value } \\
\hline & Yes & No & \\
\hline & No. (\%) & No. (\%) & \\
\hline \multicolumn{4}{|l|}{ Gender } \\
\hline Female & $23(27.4)$ & $84(68.3)$ & $<0.001^{\mathrm{a}}$ \\
\hline Male & $61(72.6)$ & 39 (31.7) & \\
\hline \multicolumn{4}{|l|}{ Age (years) } \\
\hline Under 30 & $43(51.2)$ & $27(22.0)$ & $<0.001^{\mathrm{a}}$ \\
\hline 30 to 59 & $40(47.6)$ & $59(48.0)$ & \\
\hline 60 or more & $1(1.2)$ & $37(30.0)$ & \\
\hline \multicolumn{4}{|l|}{ Religion } \\
\hline Catholic & $36(42.9)$ & $60(48.7)$ & $<0.001^{\mathrm{a}}$ \\
\hline Evangelic & $0(0.0)$ & $35(28.5)$ & \\
\hline Without religion & $48(57.1)$ & $28(22.8)$ & \\
\hline \multicolumn{4}{|l|}{ Marital status } \\
\hline Single & $41(48.8)$ & $31(25.2)$ & $<0.001^{\mathrm{b}}$ \\
\hline Married & $39(46.4)$ & $74(60.2)$ & \\
\hline Widow & $1(1.2)$ & $15(12.2)$ & \\
\hline Divorced & $3(3.6)$ & $3(2.4)$ & \\
\hline \multicolumn{4}{|l|}{ Monthly income ${ }^{c}$} \\
\hline Without income & $27(32.1)$ & 49 (39.8) & $0.338^{\mathrm{a}}$ \\
\hline Until 1 minimum wage & $47(56.0)$ & $56(45.6)$ & \\
\hline Between 1 and 2 minimum wages & 10 (11.9) & $18(14.6)$ & \\
\hline \multicolumn{4}{|l|}{ Schooling } \\
\hline Illiterate & $16(19.0)$ & $43(35.0)$ & $0.025^{\mathrm{b}}$ \\
\hline 1 to 9 years of study & $32(38.1)$ & $34(27.6)$ & \\
\hline 10 to12 years of study & 36 (42.9) & $43(35.0)$ & \\
\hline Above 12 years of study & $0(0.0)$ & $3(2.4)$ & \\
\hline \multicolumn{4}{|l|}{ Occupation } \\
\hline Employed & $57(67.9)$ & 38 (30.9) & $<0.001^{\mathrm{a}}$ \\
\hline Unemployed & $27(32.1)$ & $50(40.6)$ & \\
\hline Retired/Pensioner & $0(0.0)$ & 35 (28.5) & \\
\hline
\end{tabular}

\section{Discussion}

In the study made, a high prevalence of risk consumption of alcohol was observed strongly associated to the male sex, to the population between 18 and 30 years of age, to the users who did not have any religion, single and had some time of occupation. The sample presented rates of risk consumption of alcohol (40.6\%) similar to other national studies. It also confirms another aspect concerning the standard of consumption of alcohol related 
do gender, widened described by the literature in which men presented a higher risk consumption than the women, reaching twice as much [7] [9].

Based on the results found, a variable which is still little studied, can influence in the pattern of consumption of alcohol it is religion, in this research it was possible to observe quite a relevant significance among the users who presented risk consumption, $57.1 \%$ did not have any religion. Therefore, it is supposed that the religion can act as a protecting factor regarding the consumption of alcohol in the population under study. So, it is evident that belonging to some religious practice is directly associated to a smaller consumption of psycho-active substances as alcohol [10]. The presence of religion was reported as a protecting factor to the use of psycho-active substances in another study [11].

As to the age range, the risk consumption among youths between 18 and 30 years of age was observed. It is known that alcohol is frequently used in the adolescence, a period of transition between the dependence from the parents to a condition of personal autonomy marked by intense modification of biopsychosocial nature, and for that, characterized by a greater vulnerability to the adoption of risk behavior, such as the use and abuse of substances [12]. The present study showed that $51.2 \%$ of the researched subjects were among the risk age range, which confirms the studies, reporting that the highest incidence of alcohol consumption is among the subjects between eleven in 11 to 27 years of age [7] [12] [13].

So, when considering the group of youths such as the one with the highest risks of disorders related to alcohol, the prevalence of the standards of consumption under this demographic segment needs to have a more intense monitoring in order to take early actions against more important disorders [9].

Regarding marital status, few studies use this social demographic variable. When analyzed, this variable did not present significance or it was not used for crossing and association [9] [13]. Another study showed that the abusive consumption of the alcohol is directly linked to the conjugal situation, single [14] and another study highlighted that the married situation presented association to the reduction of alcoholic beverages intake [15].

The present study identified a significant percentage concerning the variable above mentioned, in which those users who presented risk consumption, $48.8 \%$ were single, and among those who did not present risk consumption, $60.2 \%$ were married. This variable can be associated to a higher risk consumption of alcohol, once the age range was predominantly formed by youths. A study confirmed the idea that the risk consumption of alcohol is occurring each time earlier, in an age range between 14 and 29 years of age, in which the highest prevalence for drinking was observed [16].

The variables schooling and monthly income did not present a statistically significant association with the abuse of alcohol in this study. As to the variable regarding the occupation of the users, the results did not confirm some studies that report that the men who did not work presented a higher rate of prevalence, $65.0 \%$ higher regarding those who were working [14]. So, this study brings a new profile of risk consumption, showing that $67.9 \%$ of the users had an occupation, which is directly associated to risk consumption.

The findings that associate the abusive consumption of alcohol by men who are young, single, without a religion and with an occupation, propose reflections on the social role of this consumption and their representations for this specific group. According to that, it is important to consider the preparation of the health professional facing the development of preventive activities related to the consumption of alcoholic beverages, especially the nurse of Primary Attention to Health in order to have an early identification of risk consumption and occasional prevention of the worsening of the disorders resulting from this consumption.

\section{Conclusions}

In this study, a high prevalence of risk consumption of alcohol was observed, and based on this datum, the identification of the socio-demographic segments more vulnerable to the abusive consumption of alcohol is extremely relevant, as well as the identification of the pattern of consumption of alcohol of the subjects, above all in the services of Primary Attention, in order to trace strategies for this specific population.

Facing this information, the training of the professional of primary health is important, especially the nurse, in order to have adequate approach to these users, to early identify the risk of the consumption to promote health among these users through information on the harm of excessive use of alcohol and to help in the prevention of disorders caused by it.

The instrument of research used in this study, AUDIT, showed to be quite effective during its application in primary attention to health for being fast and quite simple, which makes its application in this level of assistance 
feasible, especially with the intention to map the area of acting of the Family Health Unit in order to have specific interventions according to the profile of the risk consumption of each area.

The limitation of this study is related to its area of coverage which is limited to one Family Health Unit. So, other studies regarding the risk consumption of alcohol should be made in this scope of primary attention and are recommended in the pursuit of a greater territorial mapping and better planning of specific actions for each community according to their profile of consumption.

\section{References}

[1] Abreu, Â.M.M., Lima, J.M.B., Matos, L.N. and Pillon, S.C. (2010) Alcohol Use and Traffic Accidents: A Study of Alcohol Levels. Revista Latino-Americana de Enfermagem, 18, 513-520. http://dx.doi.org/10.1590/S0104-11692010000700005

[2] Barbosa, N.J., Mangueira, S.O., Albuquerque, J.G. and Guimarães, F.J. (2013) O cuidado de enfermagem a pacientes alcoolistas: Percepção da equipe de enfermagem. Revista Brasileira de Pesquisa em Saúde, 15, 88-93.

[3] Moretti-Pires, R.O. and Corradi-Webster, C.M. (2011) Implementation of Brief Intervention for Problematic Alcohol Use in Primary Health in the Amazon Context. Revista Latino-Americana de Enfermagem, 19, 813-820. http://dx.doi.org/10.1590/S0104-11692011000700020

[4] Corradi-Webster, C.M., Laprega, M.R. and Furtado, E.F. (2005) Evaluación Del desempeño Del CAGE con pacientes psiquiátricos ambulatorios. Revista Latino-Americana de Enfermagem, 13, 1213-1218. http://dx.doi.org/10.1590/S0104-11692005000800017

[5] Vargas, D., Oliveira, M.A.F. and Araújo, E.C. (2009) Prevalence of Alcohol Addiction among Users of Primary Healthcare Services in Bebedouro, São Paulo State, Brazil. Cadernos de Saúde Pública, 25, 1711-1720.

[6] Reis, F.B., Ciconelli, R.M. and Faloppa, F. (2002) Pesquisa científica: A importância da metodologia. Revista Brasileira de Ortopedia, 37, 51-55.

[7] Magnabosco, M.B., Formigoni, M.L.O.S. and Ronzani, T.M. (2007) Avaliação dos padrões de uso de álcool em usuários de serviços de Atenção Primária à Saúde de Juiz de Fora e Rio Pomba (MG). Revista Brasileira de Epidemiologia, 10, 637-647. http://dx.doi.org/10.1590/S1415-790X2007000400021

[8] Abrel, A.M.M., Jomar, R.T. and Paixão, L.A.R. (2011) Alcohol Use Disorders Identification Test (AUDIT) e sua aplicabilidade na atenção primária à saúde. Revista APS, 15, 113-117.

[9] Abreu, Â.M.M., Jomar, R.T., Souza, M.H.N. and Guimarães, R.M. (2012) Harmful Consumption of Alcoholic Beverages among Users of a Family Health Unit. Acta Paulista de Enfermagem, 25, 291-295. http://dx.doi.org/10.1590/S0103-21002012000200021

[10] Silva, L.V.E.R., Malbergier, A., Stempliuk, V.A. and Andrade, A.G. (2006) Factors Associated with Drug and Alcohol Use among University Students. Revista de Saúde Pública, 40, 280-288. http://dx.doi.org/10.1590/S0034-89102006000200014

[11] Wallace Jr., J.M., Brown, T.N., Bachman, J.G. and Veist, T.A. (2003) The Influence of Race and Religion on Abstinence from Alcohol, Cigarettes and Marijuana among Adolescents. Journal Study Alcohol, 64, 843-848.

[12] Laranjeira, R., Pinsky, I., Zalesky, M. and Caetano, R. (2007) Levantamento Nacional sobre Padrões do Consumo de Álcool na População Brasileira. http://bvsms.saude.gov.br/bvs/publicacoes/relatorio_padroes_consumo_alcool.pdf

[13] Rocha, L.A., Lopes, A.C.F.M.M., Martelli, D.R.B., Lima, V.B. and Martelli-Júnior, H. (2011) Consumo de álcool entre estudantes de faculdades de Medicina de Minas Gerais, Brasil. Revista Brasileira de Educação Médica, 35, 369-375. http://dx.doi.org/10.1590/S0100-55022011000300010

[14] Guimarães, V.V., Florindo, A.A., Stopa, S.R., César, C.L.G., Barros, M.B.A., Carandina, L. and Goldbaum, M. (2010) Consumo abusivo e dependência de álcool em população adulta no Estado de São Paulo, Brasil. Revista Brasileira de Epidemiologia, 13, 314-325. http://dx.doi.org/10.1590/S1415-790X2010000200013

[15] Karlamangla, A., Zhou, K., Reuben, D., Greendale, G. and Moore, A. (2006) Longitudinal Trajectories of Heavy Drinking in Adults in the United States of America. Addiction, 101, 91-99. http://dx.doi.org/10.1111/j.1360-0443.2005.01299.x

[16] Ferreira, L.N., Sales, Z.N., Casotti, C.A., Bispo Júnior, J.P. and Braga Júnior, A.C.R. (2011) Perfil do consumo de bebidas alcoólicas e fatores associados em um município do Nordeste do Brasil. Cadernos de Saúde Pública, 27, 1473-1486. http://dx.doi.org/10.1590/S0102-311X2011000800003 


\section{Sample Questionnaire}

\section{The Alcohol Use Disorders Identification Test}

1) How often do you have a drink containing alcohol?

(0) Never [Skip to Qs 9 - 10]

(1) Monthly or less

(2) 2 to 4 times a month

(3) 2 to 3 times a week

(4) 4 or more times a week

2) How many drinks containing alcohol do you have on a typical day when you are drinking?

(0) 1 or 2

(1) 3 or 4

(2) 5 or 6

(3) 7,8 , or 9

(4) 10 or more

3) How often do you have six or more drinks on one occasion?

(0) Never

(1) Less than monthly

(2) Monthly

(3) Weekly

(4) Daily or almost daily

Skip to Questions 9 and 10 if Total Score for Questions 2 and $3=0$

4) How often during the last year have you found that you were not able to stop drinking once you had started?

(0) Never

(1) Less than monthly

(2) Monthly

(3) Weekly

(4) Daily or almost daily

5) How often during the last year have you failed to do what was normally expected from you because of drinking?

(0) Never

(1) Less than monthly

(2) Monthly

(3) Weekly

(4) Daily or almost daily

6) How often during the last year have you needed a first drink in the morning to get yourself going after a heavy drinking session?

(0) Never

(1) Less than monthly

(2) Monthly

(3) Weekly

(4) Daily or almost daily

7) How often during the last year have you had a feeling of guilt or remorse after drinking?

(0) Never

(1) Less than monthly

(2) Monthly

(3) Weekly 
(4) Daily or almost daily

8) How often during the last year have you been unable to remember what happened the night before because you had been drinking?

(0) Never

(1) Less than monthly

(2) Monthly

(3) Weekly

(4) Daily or almost daily

9) Have you or someone else been injured as a result of your drinking?

(0) No

(2) Yes, but not in the last year

(4) Yes, during the last year

10) Has a relative or friend or a doctor or another health worker been concerned about your drinking or suggested you cut down?

(0) No

(2) Yes, but not in the last year

(4) Yes, during the last year

Record total of specific items here: 